Cidraes, M. Lourdes: As Lendas Portuguesas. Temas. Motivos. Categorias. Lisboa: Apenas Livros, 20I4, I46 p.

\title{
As Lendas Portuguesas. Temas. Motivos. Categorias
}

Sandra BоTO

Fundação para a Ciência e Tecnologia

CIAC - Universidade do Algarve / CLP - Universidade de Coimbra, Portugal

Os estudos de literatura tradicional careciam de um trabalho monográfico atualizado de largo espectro sobre a lenda em Portugal. Aliás, essa ausência fazia-se sentir, antes de mais, na extrema dificuldade em orientar leituras de caráter científico, que não iam além dos comentários esboçados em tentames classificativos dos diferentes géneros literários de tradição oral ${ }^{\mathrm{I}}$ ou das introduções mais ou menos rigorosas de colectâneas de lendas portuguesas publicadas, muitas delas parcelares (temáticas ou regionais).

O presente livro de M. de Lourdes Cidraes, com a chancela da Apenas Livros (editora portuguesa que se tem dedicado à divulgação do património cultural português de raízes populares, onde se conta a publicação de coleções de lendas) vem justamente contribuir para colmatar esta grave falta, ao oferecer ao leitor uma panorâmica geral sobre a lenda em Portugal, extremamente bem sustentada e ancorada na abundância de comentários que refletem a singular erudição da autora no que ao corpus lendário português diz respeito. Com efeito, a obra prévia que Cidraes já dedicou a este assunto, cujas referências são passíveis de consulta na tão bem nutrida quanto útil «Bibliografia» (p. II5-I2I) que acompanha As Lendas Portuguesas é indicadora do elevado grau de preparação da autora neste domínio concreto e augura por si só um trabalho pautado pelo máximo rigor. Assim é, de facto.

Apresentado como produto do projeto de investigação ADLOT (Arquivo Digital da Literatura Oral Tradicional), ${ }^{2}$ este livro caracteriza-se por oferecer ao leitor uma ferramenta - "grelha" aberta», nas palavras da autora (p. Io4)- de classificação do corpus lendário português, que «se integra na classificação geral elaborada por João David Pinto-Correia» (p. IO4) e que, pelo exposto, se encontra espelhada na proposta classificativa desenvolvida no âmbito do mencionado projeto. O leitor interessado poderá, assim, conhecer online $e^{3}$ a classificação das lendas portuguesas, a mesma que $\mathrm{M}$. de Lourdes Cidraes oferece, fundamentada, neste livro, e à qual deixarei aqui algumas nótulas.

AsLendas Portuguesas divide-seem duas partes fundamentais, segundoesclarece a própria autora na «Nota Prévia» (p. 7). Num primeiro momento elabora-se um estado da arte da investigação sobre a lenda em Portugal (p. I4-I8), não sem uma

I. Lembro, a título exemplificativo, o artigo de João David PINTO-CORREIA: «Os géneros da literatura oral tradicional: contributo para a sua classificação». RILP - Revista Internacional de Língua Portuguesa no 9 (Julho de I993): 63-69.

2. Trata-se de um projeto financiado pela Fundação para a Ciência e Tecnologia de Portugal, recentemente desenvolvido no Centro de Tradições Populares «Professor Manuel Viegas Guerreiro» da Faculdade de Letras da Universidade de Lisboa, coordenado pelo Professor João David Pinto-Correia e que a Doutora Maria de Lourdes Cidraes integrou.

3. Em <http://www.adlot.fl.ul.pt/> [consulta a 30/o8/20I6].

Estudis de Literatura Oral Popular, núm. 5, 20I6, I3I-I36 | DOI: IO.I7345/elop20I6I3I-I36 ISSN: 20I4-7996 | http://revistes.urv.cat/index.php/elop 
chamada de atenção prévia (necessária e bastante proveitosa, sublinhe-se) para os complexos problemas de definição que se levantam à lenda enquanto género literário tradicional. Estes mesmos problemas, que a investigadora resume entre as páginas 9 e I4, encontram-se obviamente na origem das dificuldades colocadas à classificação das lendas ao mesmo tempo que, acrescente-se, justificam também o desinteresse que a crítica manifesta sobre este género tradicional em Portugal, se confrontarmos com o panorama crítico atual do conto e do romanceiro, para citar dois exemplos contrários flagrantes. ${ }^{4}$ Já a segunda parte da obra (p. I9IO2), dedica Cidraes à apresentação da sua proposta de classificação das lendas portuguesas, comentada exaustivamente, categoria por categoria. Em termos de extensão, notamos que a esta segunda parte a investigadora dedica um desigual esforço que corresponde a um superior investimento no desenvolvimento das ideias e dos argumentos, já que é aqui que reside a originalidade da sua proposta.

Contudo, tendo em conta o défice bibliográfico apontado no início, terse-ia apreciado um ênfase mais significativo na exposição teórica patente na primeira parte do estudo, sugerindo-se até um confronto efetivo com o estado da investigação sobre a lenda noutras tradições. A adoção de uma perspetiva comparatista poderá eventualmente vir a abrir pistas e a oferecer soluções partilhadas para a classificação e, consequentemente, para o estudo da lenda em Portugal, na esteira, por exemplo, do trabalho do Groupe de Recherches Européen sur les Narrations Orales, que a própria autora menciona de passagem (p. I4).

De resto, um dos objetivos assumidos com a publicação desta proposta de classificação será o de «disponibilizar preciosos instrumentos para ulterior trabalho de análise e interpretação» (p. I4), partindo do princípio de que o levantamento e o posterior estabelecimento de taxonomias precederá necessariamente a fase analítica sobre as narrativas lendárias. Se é compreensível que a carência de uma taxonomia estável dificulte a produção de bibliografia crítico-analítica sobre a lenda tradicional portuguesa, é bem verdade também que cabe por vezes ao estudo direto das versões o mérito de se produzirem avanços significativos no que respeita a questões de classificação e à determinação das origens dos relatos (e não faltam levantamentos de narrativas lendárias que o permitam, em Portugal, como principalmente provam as plataformas $\mathrm{APL}^{5} \mathrm{e}$, mais recentemente, ADLOT). ${ }^{6} \mathrm{~A}$ ser assim, a revisão da «"grelha" aberta» a que se refere Cidraes poderá beneficiar não só do prosseguimento do trabalho de recolhas a efetuar futuramente na tradição

\footnotetext{
4. Note-se, como bem salienta a autora (p. 9 e II), que o conto e o romanceiro beneficiam de sistemas de classificação estáveis e internacionalmente reconhecidos, ao invés do que sucede com a lenda (embora não isentos de problemas e incoerências, bem entendido) que são por seu turno propícios à produção de investigação sobre os próprios textos, a partir das mais diferentes perspectivas críticas.

5. Trata-se da sigla do Arquivo Português de Lendas, desenvolvido pelos investigadores do Centro Ataíde Oliveira da Universidade do Algarve, Isabel Cardigos dos Reis e Paulo Correia. Encontra-se disponível em linha em <http://www.lendarium.org/>.

6. O caso do estudo do romanceiro da tradição oral moderna, numa perspetiva comparativa, é exemplar a este nível. A análise textual tem vindo a conduzir, inclusivamente, à reclassificação de determinados temas. Veja-se, por exemplo, o caso do romance «Nau Catrineta», que veio a comprovar-se não ser de origem portuguesa, como supunha Almeida Garrett em meados do século XIX (teoria que foi replicada por eminentes eruditos que abordaram o assunto desde então até bem entrado o século xx) e que muito menos tem por base um naufrágio histórico concreto como aventava o escritor romântico português.
} 
oral, mas também dos urgentes estudos críticos que se venham a apresentar à comunidade científica sobre o lendário português, partindo da firme assunção de que, no momento atual, os avanços a atingir em qualquer uma das três vertentes (recolha, classificação e análise do corpus de lendas) produzirão efeitos positivos nas outras duas, numa lógica de natural interdependência que justifica apostar em todas elas em simultâneo e sem receios.

Importa referir também que a classificação das lendas portuguesas aqui apresentada parte de uma base de trabalho de referência nacional (e não só, creio). Penso em concreto no labor desenvolvido pelos investigadores do já mencionado APL, tal como a autora sublinha em diversos lugares da obra. Na verdade, um confronto entre o sistema classificativo adotado no APL e aquele agora proposto é revelador de uma estreita filiação do segundo em relação ao primeiro, com algumas variantes que se explicam por, de um modo geral, a nova proposta de $\mathrm{M}$. de Lourdes Cidraes ostentar uma tendência para a criação de categorias textuais mais finas do que o APL.

Detenhamo-nos, então, sobre a proposta de classificação das lendas portuguesas oferecida na obra em questão, atentando numa seleção de algumas das relevantes questões por ela suscitadas. Como o próprio subtítulo esclarece Temas. Motivos. Categorias- será uma perspetiva múltipla a que preside à elaboração da tábua classificatória apresentada em forma de índice entre as páginas I9 e 2I, que a autora comentará com notável detalhe e cuidado daí em diante. Dividemse, nesta tábua, as lendas portuguesas em seis grandes categorias, a saber: «Lendas Sagradas», «Lendas de Forças e Seres Sobrenaturais», «Lendas Históricas», «Lendas Etiológicas», «Lendas Iconográficas» e uma «Varia». Cada uma delas particularizar-se-á, por sua vez, em numerosas subcategorias.

Observa-se, contudo, que uma variedade de critérios preside à criação das categorias, facto à partida gerador de problemas de difícil solução. Uma ampla categoria como a das «Lendas Sagradas» (ponto I da tábua, p. I9) organiza-se, por um lado, em ciclos temáticos dedicados à vida de personagens bíblicas como Jesus Cristo (I.I) ou a Nossa Senhora (I.2) e, por outro, alberga subcategorias delineadas com base em motivos tradicionais como os das «Punições Divinas» (I.5) ou das «Imagens Andarilhas» (I.6). A das «Lendas Históricas» (3, p. 2O-2I) afigura-se ainda mais conflituosa, na medida em que mistura distintas categorias conceptuais, como os ciclos de temática histórica cronologicamente organizados («Lendas Anteriores à Fundação de Portugal» - 3.I, «Lendas da Fundação de Portugal» - 3.2, «Lendas da Defesa da Independência» - 3.3, com categorias que não obedecem especificamente a critérios de historicidade como são exemplo a dos «Amores Trágicos» - 3.I3, a das «Profecias e Prodígios» - 3.I4 ou a das «Maldições, Castigos e Expiações» - 3.I5, que assentam maioritariamente em topoi folclóricos verdadeiramente transversais às diversas classes de lendas que se possam estabelecer.

É certo que as múltiplas propostas de classificação da literatura tradicional nos seus variados géneros têm vindo a refletir esta mesma heterogeneidade de critérios desde, pelo menos, o século XIX, sintoma, afinal, das inúmeras (algumas vezes insolúveis) questões levantadas por textos que vivem justamente da sua errância em variação e contaminação, comungando entre eles motivos e fórmulas que configuram a natureza deste tipo de literatura. Muito a propósito, Michelle Débax, 
num estudo preliminar apenso a uma antologia do romanceiro espanhol, ${ }^{7}$ analisa e critica diversos sistemas de classificação do romanceiro desenvolvidos durante o século xx, nos quais são preponderantes, com alguma variação, o hibridismo de critérios, e nos quais a origem e o conteúdo dos romances coexistem como critérios válidos para agrupar os temas.

Se, na realidade, o próprio romanceiro não se esquivou parcialmente a uma classificação que incorpora o motivo folclórico como elemento aglutinador, ${ }^{8}$ no caso da lenda essa tentação/necessidade acentua-se exponencialmente em função das próprias características simbólicas e maravilhosas do relato lendário, como deixa bem transparecer a classificação de M. de Lourdes Cidraes, que recorre ao motivo com frequência.

Ainda a respeito deste tipo de classificação, opina a professora Débax que «Diferente de la tradicional vendría a ser la distribución de los romances, si se tomaran en cuenta tales motivos. Pero como un romance contiene varios motivos, el problema sería la determinación del motivo principal». ${ }^{9}$ Ora, com este mesmo escolho se depara o leitor que atente na classificação da lenda em questão: a enorme dificuldade em determinar «a dominante temática» (p. Io4) obriga à inclusão das lendas em diferentes categorias (à semelhança do que já sucedia com o sistema de classificação do APL, de resto). Infelizmente, embora reconheça este facto, a meu ver a autora pouco insiste neste critério de desambiguação, ou seja, na procura dessa dominante, o que contribui para que se repliquem, nalgumas categorias, comentários já expostos a propósito de outras categorias mas em relação aos mesmos textos. Por seu turno, talvez essa tentativa de determinação de uma dominante temática desencorajasse a criação de subcategorias que acabam por reproduzir outras subcategorias já existentes noutras áreas temáticas da tábua. De modo a ilustrar o que acabo de expor, questione-se, por exemplo, a pertinência da subcategoria 3.I6 («Fundação de Castelos e Povoações»), pertencente às «Lendas Históricas», que colide substancialmente com o espírito das consideradas «Lendas Etiológicas» e que, portanto, se me afigura desnecessária.

Consideraríamos benéfica, pelo que fica dito, uma tentativa futura de eliminar o maior número possível de inclusões de lendas em múltiplas categorias em simultâneo, bem como os comentários correspondentes, repetições e remissões, a partir da aplicação do conceito de «dominante temática» ao relato lendário (independentemente do necessário levantamento dos restantes motivos eventualmente presentes em cada texto).

Entende-se, ainda assim, que foi sob os mais sérios princípios de rigor, fundados numa cuidada análise textual, que a autora se viu na necessidade de

7. DÉBAX, Michelle (I982): Romancero, edición, estúdio y notas de Michelle Débax. Madrid: Alhambra, p. 3-I5I.

8. Basta pensarmos em muitas das categorias adotadas na classificação do romanceiro português presente na obra de referência de FERrÉ, Pere; Cristina CARINHAS (2000): Bibliografia do Romanceiro Português da Tradição Oral Moderna (I828-20oo). Madrid: Instituto Universitario Seminario Menéndez Pidal, que não são de origem histórica, épica, bíblica, clássica ou carolíngia, como são as categorias dos «Romances do regresso do marido», dos «Romances de esposa infeliz» ou dos «Romances de Morte Personificada», para não me estender demasiado na listagem.

9. DéBAX, Michelle (1982): Romancero, edición, estúdio y notas de Michelle Débax. Madrid: Alhambra, p. 92. 
ampliar o número de categorias de lendas previsto no APL, até porque muito possivelmente domina um corpus de referência mais amplo do que o desta plataforma, embora não esclareça concretamente a extensão do mesmo. Num trabalho de confronto entre os dois sistemas de classificação, não pudemos deixar de notar, no entanto, que a divisão em mais subcategorias, apelando aos particularismos do corpus lendário da tradição portuguesa, segundo apresenta Cidraes, parece, pois, constituir um elemento gerador de maior perturbação do que um sistema classificativo mais abrangente e flexível.

Por último, na impossibilidade de esgotar aqui todos os comentários a uma tão substancial classificação das lendas portuguesas como a presente, centremonos agora naqueles que constituem talvez os mais interessantes (e polémicos) aspetos defendidos nesta grelha. Refiro-me concretamente à rejeição da categoria «Lendas Urbanas» e à adoção de uma outra designada "Lendas Iconográficas». ${ }^{\text {Io }}$ A partir da minha leitura, esta atuação resolve um problema, por um lado, mas coloca um novo, por outro.

Passemos diretamente ao novo problema. Servindo-me das palavras da autora, as «Lendas Iconográficas» «Explicam a origem e o significado das representações iconográficas» (p. 97) subdividindo-se em «Iconográfico-interpretativas», «Iconográfico-heráldicas» e «Iconográfico-religiosas» (p. 97-IO2). Dos múltiplos exemplos aludidos pela investigadora para cada uma das categorias, poderemos destacar as lendas interpretativas da tumulária medieval (p. ex. as interpretações suscitadas pelo programa iconográfico dos túmulos de D. Pedro I e de D. Inês de Castro) para o primeiro grupo (p. 98-99), a interpretação do enigmático brasão da cidade de Coimbra, para o segundo (p. IOo), ou as explicações para a «origem e significado de símbolos, emblemas e alegorias presentes nas representações iconográficas referentes a Cristo, à Virgem, aos santos nacionais e a episódios bíblicos.» (p. IO2), como seja a nau dos corvos deS. Vicente, por exemplo, referente ao terceiro grupo (p. IO2). É, todavia, com muita perplexidade que, de acordo com a perspetiva apresentada, concluímos que é à necessidade de interpretar elementos iconográficos como os mencionados que assiste a formação de relatos lendários. Por um lado, vários dos exemplos de iconografias enigmáticas convocados pela autora consistem em problemas do foro da História da Arte, (parte significativa da bibliografia na qual M. de Lourdes Cidraes se apoia pertence curiosamente a esta área científica), que por este campo do saber são tratados e cujas hipóteses interpretativas não se encontram adstritas ao território lendário mas quanto muito bebem na lenda possibilidades de leitura, sempre que a História não a negue através de evidências. Por outra parte, é expectável, tendo em mente os conhecidos mecanismos de interação entre tradição popular e tradição erudita (nos seus mais diversos registos) que uma representação iconográfica (enigmática ou não) corresponda, ela sim, a uma forma de expressão de uma eventual lenda pré-existente que deve ser considerada. Insisto, para melhor esclarecer a questão, que o atual desconhecimento de um símbolo ou do significado de uma qualquer representação não gera necessariamente uma lenda, mas uma indagação para a qual se formulam hipóteses, algumas das quais até cientificamente estruturadas, como se observa nalguns dos exemplos aduzidos por M. de Lourdes Cidraes. Mas

Io. Penso, nomeadamente, no confronto com o sistema classificativo do Arquivo Português de Lendas, onde figura a primeira categoria e é omitida a segunda. 
mesmo assim, admitindo a existência de um relato lendário associado a uma representação iconográfica (embora não suscitado necessariamente por ela, claro está), a sua atribuição a uma das restantes categorias aventadas pela autora na sua grelha afigura-se, então, pertinente e desejável, de acordo com as características particulares da narrativa, tornando por conseguinte dispensável a das «Lendas Iconográficas».

Regressemos, por fim, ao problema solucionado, a meu ver, por esta classificação de M. de Lourdes Cidraes, com recurso a uma bateria argumentativa sólida, que lamentavelmente não foi transposta para o caso das «Lendas Iconográficas»: a rejeição das «Lendas Urbanas» como categoria, ao contrário do que considera o APL (ver p. I7-I8). Desvalorizando (e bem, na minha perspetiva) as particularidades de transmissão deste tipo de relatos (com os media a assumir grandes responsabilidades quanto à sua transmissão e garantia de credibilidade enquanto fenómenos «reais» e aterradores), Cidraes contesta que estas lendas «contemporâneas» configurem uma tipologia específica com base nestes critérios de transmissão, de crença e de conteúdo (pelo mesmo prisma, contudo, a transmissão de uma lenda numa representação iconográfica não a torna especial por si só, facto que a investigadora não considerou). E acrescenta, com enorme lucidez:

Os exemplos mais referidos no território português são as várias versões da «Noiva fantasma» ou «O fantasma que pede boleia» e de «O roubo de órgãos». Estas narrativas podem traduzir a permanência de receios e temores antigos, mas ainda vivos em áreas das sociedades contemporâneas onde a influência dos media é grande ou podem resultar da intenção de atribuir actos hediondos a um determinado grupo populacional percebido como estranho e como concorrente, caso das diversas versões do «Roubo de órgãos», atribuído no passado a judeus e recentemente a comerciantes chineses (p. I7-I8).

Para de seguida rematar, com agudeza, que: «Deste modo, parece-me difícil considerar estas narrativas como uma categoria específica de lendas, dado que podem incluir-se nas lendas de forças e seres sobrenaturais / fantasmas, ou na miscelânea / casos estranhos» (p. I8). Sugerimos, como conclusão, que este mesmo exercício de exclusão de categorias lendárias desnecessárias se aplique com proveito à totalidade do corpus analisado.

Naturalmente que o debate em torno da classificação do material lendário português não se dá por encerrado com esta proposta de classificação. Porém, todos os reparos aqui apontados acabam por diluir-se plenamente na superioridade do trabalho realizado. Resta encorajar vivamente a que da pena e do imenso saber desta investigadora surjam novos contributos para o estudo deste género, já que só partindo de uma estabilização classificativa das tradições nacionais se chegará ao almejado sistema taxinómico de reconhecimento internacional. 